\title{
Dominant Design or Multiple Designs: The Flash Memory Card Case
}

\author{
Henk J. de Vries, Joost P.M. de Ruijter and Najim Argam
}

\begin{tabular}{|l|l|}
\hline \multicolumn{2}{|l|}{ ERIM REPORT SERIES RESEARCH IN MANAGEMENT } \\
\hline ERIM Report Series reference number & ERS-2009-032-LIS \\
\hline Publication & May 2009 \\
\hline Number of pages & 20 \\
\hline Persistent paper URL & http://hdl.handle.net/1765/16039 \\
\hline Email address corresponding author & hvries@rsm.nl \\
\hline Address & Erasmus Research Institute of Management (ERIM) \\
& RSM Erasmus University / Erasmus School of Economics \\
& Erasmus Universiteit Rotterdam \\
& P.O.Box 1738 \\
& 3000 DR Rotterdam, The Netherlands \\
& Phone: + 31 10 408 1182 \\
& Fax: + 31 10 408 9640 \\
& Email: info@erim.eur.nl \\
& Internet: $\quad$ www.erim.eur.nl \\
\hline
\end{tabular}

Bibliographic data and classifications of all the ERIM reports are also available on the ERIM website: www.erim.eur.nl 


\section{ERASMUS RESEARCH INSTITUTE OF MANAGEMENT}

\section{REPORT SERIES}

\section{RESEARCH IN MANAGEMENT}

\begin{tabular}{|c|c|}
\hline \multicolumn{2}{|c|}{ ABSTRACT AND KEYWORDS } \\
\hline Abstract & $\begin{array}{l}\text { Literature suggests that in battles between competing designs, ultimately one design will emerge } \\
\text { as dominant to the detriment of the others. Various factors and forces have been identified to } \\
\text { explain this phenomenon. Yet, sometimes no dominant design emerges at all and multiple } \\
\text { competing designs coexist in the market.. The Flash Memory Card Industry provides an example } \\
\text { of this. In this study, we use this example as a case to investigate the circumstances under } \\
\text { which an industry has a tendency toward multiple designs. The case shows that a combination } \\
\text { of factors may result in multiple designs and we argue that such a combination of factors will } \\
\text { increasingly also apply in other cases. }\end{array}$ \\
\hline Free Keywords & dominant design, multiple designs, standards wars, flash memory cards \\
\hline Availability & $\begin{array}{l}\text { The ERIM Report Series is distributed through the following platforms: } \\
\text { Academic Repository at Erasmus University (DEAR), DEAR ERIM Series Portal } \\
\text { Social Science Research Network (SSRN), SSRN ERIM Series Webpage } \\
\text { Research Papers in Economics (REPEC), REPEC ERIM Series Webpage }\end{array}$ \\
\hline Classifications & $\begin{array}{l}\text { The electronic versions of the papers in the ERIM report Series contain bibliographic metadata } \\
\text { by the following classification systems: } \\
\text { Library of Congress Classification, (LCC) LCC Webpage } \\
\text { Journal of Economic Literature, (JEL), JEL Webpage } \\
\text { ACM Computing Classification System CCS Webpage } \\
\text { Inspec Classification scheme (ICS), ICS Webpage }\end{array}$ \\
\hline
\end{tabular}




\title{
Dominant design or multiple designs:
}

\section{The flash memory card case ${ }^{1}$}

\author{
Henk J. de Vries", Joost P.M. de Ruijter and Najim Argam \\ Rotterdam School of Management, Erasmus University, Rotterdam, the Netherlands
}

\begin{abstract}
Literature suggests that in battles between competing designs, ultimately one design will emerge as dominant to the detriment of the others. Various factors and forces have been identified to explain this phenomenon. Yet, sometimes no dominant design emerges at all and multiple competing designs coexist in the market.. The Flash Memory Card Industry provides an example of this. In this study, we use this example as a case to investigate the circumstances under which an industry has a tendency toward multiple designs. The case shows that a combination of factors may result in multiple designs and we argue that such a combination of factors will increasingly also apply in other cases.
\end{abstract}

Keywords: dominant design; multiple designs; standards wars; flash memory cards

\footnotetext{
${ }^{1}$ Paper to be published in Technology Analysis \& Strategic Management.

*Corresponding author. Email: hvries@rsm.nl
} 


\section{Introduction}

Many technologies currently in use struggled with similar competing products before gaining the dominant design. The famous case of the VHS videotape is the best known example of such a battle. The emergence of a dominant design is difficult to predict and cannot be entirely explained by economic literature. A dominant design is not necessarily the technologically superior one, nor will it meet the needs of a particular class to the same extent as a customized design, (Anderson and Tushman 1990; Suarez and Utterback 1995). = The emergence process for dominant designs has typically been viewed as a black box process involving a sophisticated interaction of technological and non-technological factors' (Lee et al. 1995). A dominant design does not always emerge, even many years after product introduction. Game consoles are an example: Microsoft Xbox, Nintendo Wii, and Playstation 3.

A dominant design may, in particular, be expected in the case of network externalities. These apply to cases where the benefits from using a technology or product increase with the number of other users of the same technology or product (Katz and Shapiro 1985, Farrell and Saloner 1985, Rohlfs 1997, Birke and Swann 2006). For instance, in a telephone network with n users, the total number of possible connections is $1 / 2 n(n-1)$ so the more users, the more utility there is for an individual user. Network externalities are also referred to as network effects (Katz and Shapiro 1985; Liebowitz and Margolis 1994) or positive external consumption benefits (Katz and Shapiro 1986). Indirect network effects arise because bigger networks attract a larger range of complementary products and services which contribute to their dominance. Factors in favour of one design to emerge include design features (compatibility, technological superiority, flexibility), mechanisms (bandwagon effect, network externalities, information increasing returns), stakeholder-related factors (current and previous installed base, regulator), strength of the party or parties (financial strength brand, brand reputation) and strategic factors (pricing strategy, timing of entry, marketing communications) (Van de Kaa et al. 2007). In this paper, we will limit the choice of designs with network externalities.. The intriguing question is how, despite this, can two or more designs co-exist rather than converge into a single dominant design?

First we present known success factors in favour of multiple designs, noting that these may be identical to factors that negatively influence the emergence of a dominant design. Next 
we investigate the applicability of these factors in a case study. We have chosen the flash memory card industry because several designs have co-existed for more than a decade. We end by identifying conditions for continued co-existence of multiple competing designs.

\section{Dominant design definition}

The definition of a dominant design has evolved from a broad and possibly tautological one to a more specific one (Srinivasan, Linien, and Rangaswamy 2006). Utterback and Abernathy (1975) were the first authors to use the term dominant design. They defined it as _a single architecture that establishes dominance in a product category. 'A similar definition is used by Anderson and Tushman (1990) and by Tegarden, Hatfield and Echols (1999). They also use the term _single architecture' that which has become widely accepted as the industry standard. However, _widely accepted' is a rather vague description and therefore in the paper we will use a more specific definition: 'A design will be considered as the dominant one, when more than $50 \%$ of new installations in a product category use the technology. ' (Anderson and Tushman 1990). By adding _in a product category, 'the definition adds the possibility that several dominant designs can emerge in various product categories or niches at the same time. The definition does not include a geographical distinction. A design may be dominant in one part of the world whereas another design is dominant in another region. In this case, there is no global dominance. which can be the world market or a certain country or region. Combining these considerations, we can define a dominant design as: _A single architecture used by more than $50 \%$ of new installations in a product category in a certain geographic product market'.

Several authors use the term _standard" where others use _design' (Shapiro and Varian 1999a; Shapiro and Varian 1999b). Gallagher (2007) argues that the two concepts are fundamentally different. Gallagher quotes Shapiro and Varian (1999b) in defining standard as an interface format that creates a single network of compatible users." In fact, this definition includes only compatibility standards, ignoring other categories of standards: minimum quality and safety standards, variety reducing standards, and information and measurement standards (Blind 2004). According to Gallagher (2007, 372), _the key indicator of a dominant design is the durability or persistence of its architecture.' He does not define _architecture', but sees this as a much broader concept than a standard. For instance, VHS and MS-DOS are standards for VCRs 
and PCs respectively. Gallagher (2007) then considers VCRs and PCs as architectures. However, much of the dominant design literature addresses interface solutions such as VHS and MS-DOS. In this paper we include these in the concept of _design“. Gallagher (2007) suggests that network effects apply to all compatibility standards. Although this does not hold for all standards, for example in space travel it is generally true and for the purpose of this paper, Gallagher's (2007) study is particularly interesting.

Another observation by Gallagher (2007) is that dominant designs can only be recognized post hoc whereas standards can be identified before dominance is achieved. Indeed, standards are called standards because of the intention and expectation of repeated or continuous use. (De Vries 1997). If a standard achieves dominance, it can be seen as a dominant standard. In some cases, it might then also be viewed as a dominant design and therefore the distinction is not always as sharp as suggested by Gallagher. In the remaining part of this paper we will use the term =dominant design' but we will use some of the findings of standards literature in the case to which we think it applies.

\section{Factors in favour of multiple designs}

\section{Introduction}

It may take several years before a design becomes dominant. The majority of researchers assume that a dominant design will always emerge although some authors disagree with this and allow for the possibility that several designs can co-exist. (Srinivasan, Linien, and Rangaswamy 2006; Frenken, Saviotti, and Trommetter 1999). In this case _several competing technologies become established and continue to co-exist and be gradually enhanced within their individual evolution paths' (Paila 2005). In many industries, several standards may compete for years, even decades, without one technology being locked in as a dominant design. ' (Schilling 2002). How can the co-existence of multiple designs be explained? The following factors can be found in literature: 1) Distinct features resulting in product niches and consumer communities 2) Gateway technologies 3) Multi-channel end systems 4) Appropriability regime 5) Persistency. 


\section{Factor 1: Distinct features resulting in product niches and consumer communities}

Rival technologies with distinct features may be able to survive side by side because consumers might value certain product attributes more than network size. This can result in consumer communities, each having a preference for a specific attribute or feature. Hence, dominant designs can appear in product categories, while the overall technology lacks a single dominant design. For example, the current dominant design for home printers is the inkjet technology, while professional usage favours laser printer technology.. When competing designs vary in the advantages they generate for different categories of users, each may develop its own installed base with enough critical mass, and the subsequent lock-in effect prevents one from winning (Arthur 1990). Also Windrum and Birchenhall (1998) and Frenken et al. (1999) observed industries with various market niches and reported that alternative designs may compete or converge to a single design per niche. Westarp et al. (2000) report a case of geographical differences in market acceptance of a design for Electronic Data Interchange: In the USA the (American) ANSI X12 standard remained dominant whereas in Germany the (international) EDIFACT standard became most popular. The preference of American users for ANSI X12 can be explained by its installed base which gave new users no reason to use the competing standard although is the internationally accepted standard.

\section{Factor 2: Gateway technologies}

As noted above, when competing designs each have their own unique advantages for different categories of users or in specific product categories, they may develop their own installed bases, and consequently can coexist in the market. In these situations, gateway technologies can provide solutions for compatibility problems. A gateway technology establishes (ex post) compatibility between non-compatible systems. For example this can, be achieved by adapters that enable conversion from one standard to another (Baake and Boom 2001). Gateway technologies are typically functional in situations where several technologies survive and users desire some form of communication or connection among them. In such a situation, the costs of achieving compatibility should be lower than the cost of conversion to a new standard. These switching costs include the cost of acquiring new physical and human capital as well as the loss of any function that was unique to the abandoned technology (Cowan 1992). If the switching 
costs are too high, the earlier mentioned lock-in effect will arise. In brief, we can assume that when a cheap and easy technology is available which can bridge two or more incompatible products or technologies, this will work in favour of the coexistence of multiple designs. However, a gateway technology is always a sub-optimal solution in cases when there are other reasons for multiple designs.

\section{Factor 3: Multi-channel end systems}

The adapter for reaching ex post compatibility does not need to be a separate device. A firm can also adopt another firm's specifications for its product design, resulting in a hybrid product able to accommodate both technologies. Then this product has a dhannel' for interoperability with technology A and another_channel' for interoperability with technology B, or even more than two channels.' In the case of DVDs, several companies introduced writers supporting both DVD+RW and DVD-RW. Gauche (2005) argued that this concept of _Multiple Implementation" could lead to a stable structure of coexistence. Once players have invested in multiple implementation, dropping out may cause loss of market share because consumers tend to be more risk averse at later stages in the technology diffusion process (the late majority and the laggards) than their counterparts at early stages of the process (the innovators, early adopters and early majority). However, the need to have more than one channel may lead to additional cost and performance degradation (Shapiro and Varian 1999a).

\section{Factor 4: Appropriability regime}

Appropriability regime refers to environmental factors that govern an innovator's ability to capture the profits generated by an innovation (Teece 1986). ' It is the ability of a firm to protect an innovation from imitation by competitors (Lee et al. 1995). According to Levin et al. (1987), the regime of appropriability can consist of six aspects: patents, secrecy, lead time, learning curve, efficiency sales, and service effort. Teece (1986) identifies three legal instruments: patents, copyrights, and trade secrets. The appropriability regime of a company can have a positive as well as a negative effect on the emergence of a dominant design.

When a firm has a superior technology and is in the position to prevent competitors from introducing slightly deviating copies, its design may become dominant (Suarez 2004). Microsoft 
Office and Windows are clear examples of this. However, antitrust authorities may force owners of dominant technologies to provide the opportunity for competitors to also get a foothold. ${ }^{i}$ Most companies do not have the same position as Microsoft and need the support of other manufacturers to achieve dominance and may license to other manufacturers on attractive terms (Bekkers, Verspagen, and Smits 2002). Intellectual property rights may also be used to prevent the introduction of clones with features which differ slightly from the original technology which might hinder the general acceptance of this technology.

However, Srinivasan, Linien, and Rangaswamy (2006) conclude that protecting a technology can dramatically decrease the likelihood of that technology being chosen due to high prices and/or fear for _vendor lock-in‘. Tight appropriability can also lead to localized monopolies with several independent market niches. This phenomenon reduces selection pressures crucial for the emergence of a dominant design (Anderson and Tushman 1990). Specifically, tight appropriability tends to limit industry-wide learning effects, and thus results in higher R\&D expenses (Levin et al. 1987). Moreover, proprietary systems cause higher cost and poorer availability of complementary goods, resulting in a high risk of rejection.

\section{Factor 5: Persistency}

Some firms (especially multinationals) can develop some degree of persistency in support of their own solution which may enhance the chances for this design to achieve dominance. However, there is a danger of persisting even if it is already clear that there is little or no chance to win the battle and then the battle continues. De Vries (2001) gives an example of a battle for dominance between two competing e-purse systems. One bank continued investing in its system after the design of other banks had proven to be more successful, resulting in unnecessary expenditures of more than $\$ 1 \mathrm{bn}$.

\section{Interrelations between factors}

Whether or not a dominant design emerges depends on a set of interrelated factors. Lee at al. (1995), Schilling (1998) and Suárez (2004) have grouped such factors in a framework. The relative importance of the various factors may differ per case. In many cases, for example, 
government's regulations will not apply but in instances in which a government prescribes a certain design, this factor bears the most importance. More generally: battles for dominance differ (Shapiro and Varian 1999a). Therefore, just _counting' numbers of factors for single or multiple designs or weighing the factors is not necessarily meaningful. Nevertheless, Shapiro and Varian suggest that every battle for dominance (or standards war as they call it) is the same: _companies heading off to fight a standards war do not have to reinvent the wheel', and the economics underlying such battles change little, if at all, over time (Shapiro and Varian 1999b).

\section{Case Study: Flash Memory Cards}

\section{Research approach}

We have chosen to further explore factors for multiple designs in a battle which, in contrast to for instance the battle between Blu-ray and HD-DVD, has received little attention: the 'hidden battle' between flash memory card formats. Desk research provided data necessary to make an overview of the various types of memory cards, their history, and any possible industry strategies undertaken to obtain dominance in the market. Empirical data about the applicability of the factors for standard dominance and for multiple designs were determined for this case. In addition to our own desk research analysis, we decided to interview experts with both broad and in-depth knowledge of the industry, primarily supplier representatives. Despite company strategies being at stake, we managed to get face-to-face interviews with three industry representatives: marketing managers from Sony, Sandisk and Olympus. A sales representative of MediaMarkt, the largest consumer electronics retailer in Europe, was also interviewed in order to add the user perspective related to these factors, In each interview, we addressed the subsequent factors by asking three questions: 1) Is the factor present in the Flash Memory Card industry? 2) Does the factor influence the emergence of a single dominant design or of multiple designs? 3) What is the level of influence? (no influence, low influence, moderate influence, high influence). Because the interviewees might be not familiar with the factors, each factor was turned into a question. For example, the factor Network externalities' was rephrased into the following question:_Can a relation be defined between consumer value and the number of users in the network? In other words, do the benefits from using a particular memory card increase with the number of other users making use of the same memory card?' The question related to the factor 
for dominant designs _pricing‘ was Is the memory card high priced compared to its competitors? Can penetration pricing or other pricing strategies be identified?' The factor for multiple designs =Distinct features' was rephrased as: Does the memory card incorporate distinct features which might address a specific group of users, or in which a niche can be formed"? The respondents were also asked to add other factors relevant for the flash memory card case, and to provide us with additional data not available via public sources. Finally, the researchers analyzed and interpreted the findings from desk research and from the interviews and drew conclusions. It turned out that the first interview, with a marketing manager from Sony, revealed all factors. The following interviews just confirmed the findings, which shows the data are reliable despite the small number of interviews.

\section{Available flash memory cards}

The most common data storage technology is the magnetic disk or hard disk. Beyond these systems, optical systems are recognized as dominant in archival digital data storage. Despite their numerous virtues, magnetic and optical data storage systems also come with several disadvantages. For example, these systems are not always perfect, especially in small devices with limited power supply. Flash memory is a good alternative because it requires no power supply (non-volatile) and flash memory cards can be found in a wide range of portable electronic devices such as digital cameras and mp3 players. Flash memory technology may soon compete with hard drives in notebooks. Several companies produce various types of memory cards all with different dimensions. In general, these types are not interchangeable. Currently, roughly six types of flash memory cards exist. ${ }^{\text {ii }}$ Table 1 provides an overview of the available cards and background information and competitive advantages are briefly described. Additional information can be found in the endnotes. 
Table 1. Main types and subtypes of removable flash memory cards (Situation January 2006; Markets share data 2007).

\begin{tabular}{llllcc}
\hline Card Type & Size $(\mathrm{mm})$ & Manufacturer(s) & Year of & Market \\
shares in \\
\end{tabular}

1. SmartMedia (SM). SM, owned by Toshiba, was launched in 1996. It was one of the smallest and the thinnest early memory cards, and maintained the most favorable cost ratio. It used to be the favorite card for digital cameras. iii $^{\text {ii }}$

2. MultiMediaCard (MMC). MMC was developed by Siemens (Sandisk as well later on) in 1997. Nowadays, it is offered by multiple manufacturers. MMCmicro is the smallest card in the world, (backwards) compatible with other cards, without a write or copyright protection (thinner profiled) and it is available to all developers. ${ }^{\text {iv }}$

3. Memory Stick (MS). MS was developed and introduced by Sony in 1998. Sony uses this card for a range of different products and licenses it to other companies. MS Duo is the small version for pocket devices. ${ }^{\mathrm{V}}$

4. Secure Digital Card (SD). SD was introduced by multiple manufacturers in 2001. The SD card is based on the MMC card but includes a built-in security function and a write 
protection switch. It is the most common used memory card because of its small size and low power consumption. ${ }^{\mathrm{vi}}$

5. Extreme Digital-Picture Card (xD). Olympus and Fujifilm introduced xD in 2002 for use in their cameras. It is produced by Toshiba. ${ }^{\text {vii }}$

\section{Case Analysis and Results}

Table 1 includes market shares per card type (Koncept Analytics 2009) which show that in 2007 all card types had less than 25\% market share. Our interviewees mentioned that during the years, market shares have fluctuated and this is expected to continue. A certain card type might disappear but there is no tendency at all towards dominance of one single design. From a technical point of view this is an unsolved standards battle. However, from a business point of view, it is a battle for the cards suppliers, but also for the suppliers of equipment who have to decide which card format(s) to use. In the market, the battle is fought primarily over product specifications but additionally several associations have been established to promote certain card formats, e.g. the SD Card Association created in January 2000 by Matsushita Electric Industrial Co. (Panasonic), SanDisk Corporation and Toshiba Corporation. We analyze this situation by first discussing the main factors which may indicate emergence of a dominant design followed by the main factors in favour of multiple designs.

Several factors favour a single design. The use of flash memory cards is not limited to application in one product, such as a mobile phone, a copy machine or a camera. Typically, the same card is used in several products, for instance for storing data in a camera and, subsequently, for presenting the pictures somewhere else. Thus, indirect network externalities apply; the more new users, the more benefits there are per user through increased availability of complementary goods (Katz and Shapiro 1985; Katz and Shapiro 1986; Liebowitz and Margolis 1994). Increasingly, cards with pre-recorded media are available, for instance, music on the Gruvi card and route navigation software on SD and CompactFlash cards. These data files can also be seen as complementary goods providing another factor in favour of the emergence of one dominant design. Big firms, each with a good reputation, support the various card formats and in fact, each alliance is strong. However, such a balance between giants is instable and there would be a 
natural tendency for one to win. Below, we will analyze the case using the factors in favour of multiple designs we found in literature:

Factor 1: Distinct features resulting in product niches and consumer communities

The distinct features of card formats shown in Table 1 can be partly explained as a result of differences in fitness for use in different market segments. The $\mathrm{xD}$, for instance, was primarily developed for the photography market, whereas the SD was designed for music.

Factor 2: Gateway technologies

Gateway technologies are available. Various cheap and easily available adapters, converters, card readers etc. provide a high degree of interoperability across various (incompatible) platforms. Moreover, the bridge between, for instance, a digital camera and a PC, or the transfer from MP3 or software applications from a PC to a smartphone can be provided by cables (USB or Firewire) instead of by exchanging the flash memory cards.. These cables are another example of a gateway technology. Incentives for one standard, therefore, largely disappear.

Factor 3: Multi-channel end systems

Digital cameras store images on a (removable) flash memory card and several cameras have been made compatible with more than one type of card. This requires some minor software adaptations and a memory card slot in fits which multiple cards. Also, other equipment can handle more than one type of memory card. In this way ex post compatibility is achieved by means of a multi-channel end system.

Factor 4: Appropriability regime

The factor appropriability regime may promote the emergence of either one dominant design or multiple designs. The technology of the memory cards is mostly owned by the manufacturer who may extract license and royalty fees from other companies that implement their technology. Unwillingness to pay royalty fees may stimulate such firms to seek other solutions. The success of the MultiMediaCard can, in part, be explained by the fact that this format is royalty free. However, other card suppliers have acknowledged the disadvantages of 
different formats for the customers. As a consequence, more cooperation and liberated use of card specific slots is at hand. In this case, the appropriability issue partly explains the coexistence of different cards.

\section{Factor 5: Persistency}

According to our interviewees, persistency was at stake as well. In particular, Sony was mentioned: it introduced its own design exclusively for use in Sony products. Sony's devices are only compatible with their own card formats. Sony has built a tradition in persistency. Other examples include Betamax (instead of VHS), Attrac (instead of mp3), and MiniDisc. This attitude may encourage the development of competing technologies. If Sony does not provide its flash memory card specifications to other companies on reasonable terms, companies are forced not only to maintain other card formats but also to develop new formats to keep pace with technological progress. This attitude strengthens the appropriability regime factor in favour of multiple designs. Eoss of face" arguments can further lengthen the duration of multiple standards but we found no evidence for this.

\section{Other factors}

All five factors found in literature apply to this case. We can observe even more factors in favour of multiple designs:

Factor 6: Speed in technological development

Competition is, in fact, between families of cards and different cards may be introduced within each family at different moments. The speed of technological change might be the reason why a battle between cards is settled. New cards are introduced, influencing the battle but not yielding a clear winner.

Factor 7: Application drives the design

Flash memory cards can be regarded as complementary goods for host devices. The consumer's choice of the host device hardly depends on the specifications of the flash memory cards already in use as long as the consumer can solve the problem of compatibility by means of a gateway technology. The consumer will buy a camera, no matter what the card specification. If 
he is lucky, the flash memory card that fits in the camera can be used in his PC, mobile or other equipment as well. If the equipment has been prepared for interoperability with different card formats, it is more likely that the consumer's card will fit. However, if there is no compatibility a gateway technology can be used. Thus from the consumer perspective, the multiple format situation provides some inconvenience but in most cases the problem can be solved.

\section{Factor 8: Price}

A flash memory card is cheap (approx. \$ 5) compared to, for instance, a camera. If the card were more expensive, its specifications would probably get more attention from customers and it would be more difficult for suppliers to maintain different card formats. Moreover, the price of gateway technologies is important: it costs approximately $\$ 5$, so in general this is not a heavy burden.

In summary, there are a host of factors indicating one dominant design to emerge. The two factors on the demand side are, in particular, the network externalities characterizing the market and the need to exchange cards between different products..

However, a combination of factors on both the supplier and the demand side outweigh these factors and instead favours multiple cards. On the supplier side, some factors make it attractive for companies to introduce or maintain their own cards either to be used in their own products or in other products. Moreover, the speed of technological development has prompted companies to introduce new cards before a battle could turn into a victory for one of the designs. On the demand side, a combination of four factors made it relatively easy to cope with different cards. Primarily, application drives the design: consumers buy the host devices and take the related card format for granted rather than consciously choosing a certain card format. Moreover, because the cards are relatively cheap, consumers pay little, if any, attention to them. Furthermore, multi-channel end systems and gateway technologies allow them to solve the compatibility issues in a relatively easy way and then the advantages related to network externalities remain. The factors in favour of multiple designs are summarized in Table 2 . 
Table 2. Factors in favour of multiple designs

$$
\begin{array}{ll}
\text { Factors from Literature } & \text { Additional Factors from the Flash Memory } \\
& \text { Card Case }
\end{array}
$$

\begin{tabular}{lll}
\hline $\begin{array}{l}\text { Supply side } \\
\text { factors: }\end{array}$ & Distinct features & Speed in technological development \\
\cline { 2 - 3 } & Appropriability regime \\
\cline { 2 - 3 } $\begin{array}{ll}\text { Demand side } \\
\text { factors: }\end{array}$ & Gateway technologies & Application drives the design \\
& & \\
\cline { 2 - 3 } & Multi-channel end systems & Low price
\end{tabular}

\section{Conclusions and discussion}

The central research question posed here is: under which conditions is it possible for two or more similar but competing designs to co-exist, instead of converging into a single dominant design? Literature mentions factors in favour of a single design as well as for multiple designs. The latter include distinct features per customer group, gateway technologies, multi-channel end systems, persistency of firms and, in some cases, strong appropriability regimes. Our case suggests that the statement of Shapiro and Varian (1999b) that the economics underlying such battles change little, if at all, over time' is wrong. First, their perception that adapters and converters are highly imperfect does not apply in our case and we expect it is not applicable in an increasing number of other cases either. This is related to the gradual shift from =mechanical' or =analogue" towards _digital' technologies. The fact that the content on the card is digital makes it much easier to share the information through gateway technologies or to make multi-functional end systems. With analogue technologies, it was not or hardly possible to create gateway technologies or multi-functional end systems. Digital technologies have made this easier although gateways are not very good at translating semantics, e.g., from one application to another. Secondly, an increase in the speed of technological development causes the battlefield and the forces to change before the battle is resolved. 
Both developments can be seen in, for instance, the DVD case in which the technology is comparable with the Flash Memory card technology. However, the difference is in its application. There is more emphasis on pre-recorded content and therefore content providers are more important stakeholders in the DVD case. The two different types of recordable DVDs, DVD+ and DVD-, are compatible with almost every DVD player/recorder without complex mechanical changes, so why should the consumer make a choice? The battle between the nextgeneration DVD systems (Blu-ray and HD-DVD) has been resolved, at least for the time being, with Blu-ray as the winner. Some major media suppliers including Warner Brothers chose for Blu-ray, Blu-ray has won due to a combination of the factors _Strength of the network' and =Complementary goods'. There are rumours that financial compensation was decisive for Warner Brothers' shift to Blu-ray.. Toshiba, the main driver behind the HD-DVD systems, seems to persist in competing Blu-ray and has announced the DVD Download/DL standards as an alternative to Blu-ray, promising better picture quality and possible web content access. Also, they now seem to focus on the Chinese market as their starting-up market betting on their cost advantage since their discs would be cheaper than Blu-ray discs. Meanwhile, competitors like Pioneer have also been developing a new optical disc with additional features resulting in much more storage capacity. So we can observe three of our factors in favour of multiple designs: persistency, price, and speed of technological development. We will see whether these are sufficient to compensate for the strong factors in favour of Blu-ray. In this sense, it will also be important whether manufacturers will supply a dual-format player for both Blu-ray and competing discs.

In the DVD+ versus DVD- case, many manufacturers decided to bear the extra cost of producing universal players that would support both formats because of the fear of a standards war that would select one standard as dominant (Gauch 2005; Schilling 1999). In this way, multiple designs continue to exist side by side. If a chosen design becomes obsolete (and, for instance, complementary goods or services are no longer delivered) the cost of the gateway or the additional cost of a multi-functional end system should be substantially lower than that of migrating from one design to another., Another prerequisite for multiple designs is the rapid speed of technological advances. This is not a new factor but some decades ago its effect was almost always outweighed by factors favouring a single design. Gradually, this is changing. 
Currently and increasingly, technologies are digital so that cheap, easy and high-quality gateway technologies are possible or multi-channel solutions can be added at low cost. This, in conjunction with the faster speed of technological developments, would indicate that there is a higher chance that multiple designs will continue to exist. Still, predicting the outcome of design battles is difficult and definitive proof for a specific situation cannot be derived. This applies to the flash memory case as well. During the past ten years we have seen huge fluctuations in market share of card families and have found no arguments why this would change in the near future. The positive side of this continued "battle" is that it may stimulate ongoing innovations. This advantage may outweigh the inconvenience for end users who have to cope with different card formats. The markets for flash memory cards and comparable technologies for which network effects apply are dynamic making it difficult to predict the outcome of battles for dominance. Nevertheless, firms may influence the outcome of a design competition by using the set of factors favouring multiple designs presented in this study as an addition to the factors supporting a single design presented by Van de Kaa et al. (2007).

Our findings could be tested in other case studies. Both single and multiple case studies may be used (Dul and Hak 2008). Longitudinal multiple case studies might reveal whether indeed the number of standards battles resulting in a single standard is decreasing. 


\section{References}

Anderson, Philip, and Michael L. Tushman. 1990. Technological discontinuities and dominant designs: a cyclical model of technological change. Administrative Science Quarterly 35/4: 604-635.

Arthur, W. Brian 1990. Positive feedbacks in the economy. Scientific American 262/2: 92-99.

Baake, Pia, and Anette Boom. 2001. Vertical product differentiation, network externalities, and compatibility decisions. International Journal of Industrial Organization 19/1-2: 267-284.

Bekkers, Rudy N.A., Bart Verspagen, and Jan Smits. 2002. Intellectual property rights and standardization: the case of GSM. Telecommunications Policy 26/3-4: 171-188.

Berke, Daniel and G.M. Peter Swann. 2006. Network effects and the choice of mobile phones operator. Journal of Evolutionary Economics 16/1: 65-84

Blind, Knut. 2004. The economics of standards - theory, evidence, policy. Cheltenham, UK / Northampton, MA: Edward Elgar.

Cowan, Robin. 1992. High technology and the economics of standardization. In New technology at the outset: Social forces in the shaping of technological innovation, ed. Meinolf Dierkes and Ute Hoffmann, 279-300. Frankfurt am Main: Campus Verlag.

De Vries, Henk J. 1997. Standardization - What's in a name? Terminology 4/2: 55-83.

- 2001. Banking Chipcards in the Netherlands - One or two systems? Knowledge, Technology, \& Policy 14/2: $78-87$.

Dul, Jan, and Tony Hak. 2008. Case study methodology in business research. Oxford, UK: Butterworth Heinemann.

Frenken, Koen, Paolo P. Saviotti, and Michel Trommetter. 1999. Variety and niche creation in aircraft, helicopters, motorcycles, and microcomputers. Research Policy 28/1: 469-488.

Farrell, J. and G. Saloner. 1985. Standardization, compatibility, and innovation. Rand Journal of Economics 16/1: 70-83.

Gallagher, S. 2007. The complementary role of dominant designs and industry standards. IEEE Transactions on Engineering Management. 54/2: 371-379.

Gauch, Stephan. 2005. + Vs. - Impacts and Dynamics of Competing Standards of Recordable DVD-Media. In: Proceedings of the $4^{\text {th }}$ International Conference on Standardization and Innovation in Information Technology, ed. Tineke M. Egyedi and Mostafa Hashem Sherif. Piscataway, NJ: IEEE.

Katz, Michael L., and Carl Shapiro. 1985. Network externalities, competition and compatibility. American Economic Review 75/3: 424-440.

1986. Technology adoption in the presence of network externalities. Journal of Political Economy 94/4: $822-841$.

Koncept Analytics. 2009. Global Flash Memory Market: An Analysis. Vaishali, U.P., India: Kocept Analytics.

Lee, Ji-Ren, Donald O`Neal, Mark Pruett, and H. Thomas. 1995. Planning for dominance: a strategic perspective on the emergence of a dominant design. $R \& D$ Management 25/1: 3-25. 
Levin, Richard C., Alvin. K. Klevorick, Richard R. Nelson and Sidney G. Winter. 1987. Appropriating the returns from industrial research and development. Brookings Papers on Economic Activity. 3: 783-820.

Liebowitz, Stan J., and Stephen E. Margolis. 1994. Network externality: An uncommon tragedy. Journal of Economic Perspectives 8/2: 133-150.

Paila, Toni 2005. Mobile broadcast radio technologies: factors affecting the emergence of dominant design. Helsinki: Helsinki University of Technology.

Schilling, Melissa 1998. Technological lockout: An integrative model of the economic and strategic factors driving technology success and failure. Academy of Management Review 23/2: 267-284.

- 1999. Winning the standards race: Building installed base and the availability of complementary goods. European Management Journal 17/3: 265-274.

- 2002. Technology success and failure in winner- take- all markets: The impact of learning orientation, timing, and network externalities. Academy of Management Journal 45/2: 287-398.

Shapiro, Carl, and Hal R. Varian. 1999a. Information Rules - A Strategic Guide to the Network Economy. Boston, MA: Harvard Business School Press.

1999b. The Art of Standard Wars. California Management Review 41/2: 8-32.

Srinivasan, Raji, Gary, L. Linien, and Arvind Rangaswamy. 2006. The Emergence of Dominant Designs. Journal of Marketing 70/2: 1-17.

Suarez, Fernando F., and James M. Utterback. 1995. Dominant designs and the survival of firms. Strategic Management Journal 16/6: 415-430.

Suarez, Fernando F. 2004. Battles for technological dominance: an integrative framework. Research Policy, 33/2: 271-286.

Teece, David J. 1986. Profiting from Technological Innovations: Implications for Integration, Collaboration, Licensing and Public Policy. Research Policy 15/6: 285-305.

Tergarden, Linda F., Donald E. Hatfield, and Ann E. Echols. 1999. Doomed from the Start: What is the Value of Selecting a Future Dominant Design? Strategic Management Journal 20/6: 495-518.

Utterback, James, M., and William J. Abernathy. 1975. A dynamic model of process and product innovation. Omega 3/6: 639-656.

Van de Kaa, Geerten, Henk J. de Vries, Eric van Heck, and Jan van den Ende. The emergence of standards: a Metaanalysis. In: Proceedings of the $40^{\text {th }}$ Hawaii International Conference on system sciences. Piscataway, NJ: IEEE.

Von Westarp, Falk, Tim Weitzel, Peter Buxmann, and Wolfgang König. 2000. The Standardization Problem in Networks - A General Framework. In Information technology standards and standardization: a global perspective, ed. Kai Jakobs, 168-185. Hershey, PA: Idea Group Publishing.

Windrum, Paul, and Chris Birchenhall. 1998. Is product life cycle theory a special case? Dominant designs and the emergence of market niches through coevolutionary-learning. Structural Change and Economic Dynamics, 9/1: 109-134. 


\section{Notes}

${ }^{\mathrm{i}} \mathrm{See}$ http://ec.europa.eu/comm/competition/antitrust/cases/index/by_nr_75.html, last access 09232008.

ii Data up to January 2006. Since then, some changes have occurred already. For instance, the production of the $128 \mathrm{mb}$ SmartMedia card was stopped.

iii Toshiba launched SmartMedia to compete with MiniCard, CompactFlash, and PC card formats. A SmartMedia card consists of a single NAND flash chip embedded in a thin plastic card (though some higher capacity cards contain multiple, linked chips). It was one of the smallest and the thinnest of the early memory cards, and managed to maintain a favorable cost ratio as compared to the others. It lacks a built-in controller, which kept the cost down. This feature later caused problems, since some older devices would require firmware updates to handle larger capacity cards.

iv The MultiMediaCard is based on Toshiba's NAND-based flash memory, and is therefore much smaller than earlier systems based on Intel NOR-based memory such as CompactFlash. MMC originally used a 1-bit serial interface, but newer versions of the specification allow transfers of 4 or sometimes even 8 bits at a time. They have been more or less superseded by Secure Digital (SD) cards, but still see significant use because MMC cards can be used in most devices which support SD cards and they are cheaper than SD cards. RS-MMC cards (Reduced-Size MultiMediaCards) are smaller MMC cards; by using a simple mechanical adapter to elongate the card, an RS-MMC card can be used in any MMC slot. The only significant hardware licensors of RS-MMC cards were Nokia and Siemens.

" Sometimes a memory USB-stick is called memory stick, but in this study it refers to the brand name of Sony's

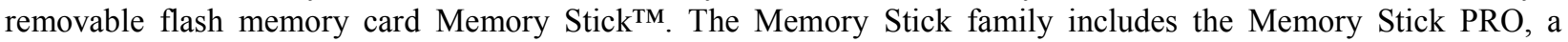
revision that allows greater maximum storage capacity and faster file transfer speeds; Memory Stick Duo, a smallform-factor version of the Memory Stick (including the PRO Duo); and the even smaller Memory Stick Micro (M2).

${ }^{v i}$ Matsushita (best known by its Panasonic brand name), Sandisk, and Toshiba first announced an agreement on a comprehensive collaboration to jointly develop, specify and widely promote a next generation secure memory card called the SD Memory Card. To create the SD card, Toshiba added encryption hardware to the already-existent MMC card, to calm music industry concerns that MMC cards would allow for easy piracy of music.

vii The xD-Picture Card is used mainly in digital cameras. Toshiba Corporation and Samsung Electronics manufacture the cards for Olympus and Fujifilm. Other brands, including Kodak, Sandisk, and Lexar, now sell xD cards as well. 


\section{Publications in the Report Series Research* in Management}

\section{ERIM Research Program: "Business Processes, Logistics and Information Systems"}

\section{9}

How to Normalize Co-Occurrence Data? An Analysis of Some Well-Known Similarity Measures

Nees Jan van Eck and Ludo Waltman

ERS-2009-001-LIS

http://hdl.handle.net/1765/14528

Spare Parts Logistics and Installed Base Information

Muhammad N. Jalil, Rob A. Zuidwijk, Moritz Fleischmann, and Jo A.E.E. van Nunen

ERS-2009-002-LIS

http://hdl.handle.net/1765/14529

Open Location Management in Automated Warehousing Systems

Yugang YU and René B.M. de Koster

ERS-2009-004-LIS

http://hdl.handle.net/1765/14615

VOSviewer: A Computer Program for Bibliometric Mapping

Nees Jan van Eck and Ludo Waltman

ERS-2009-005-LIS

http://hdl.handle.net/1765/14841

Nash Game Model for Optimizing Market Strategies, Configuration of Platform Products in a Vendor Managed Inventory (VMI) Supply Chain for a Product Family

Yugang Yu and George Q. Huang

ERS-2009-009-LIS

http://hdl.handle.net/1765/15029

A Mathematical Analysis of the Long-run Behavior of Genetic Algorithms for Social Modeling Ludo Waltman and Nees Jan van Eck

ERS-2009-011-LIS

http://hdl.handle.net/1765/15181

A Taxonomy of Bibliometric Performance Indicators Based on the Property of Consistency

Ludo Waltman and Nees Jan van Eck

ERS-2009-014-LIS

http://hdl.handle.net/1765/15182

A Stochastic Dynamic Programming Approach to Revenue Management in a Make-to-Stock Production System Rainer Quante, Moritz Fleischmann, and Herbert Meyr

ERS-2009-015-LIS

http://hdl.handle.net/1765/15183

Some Comments on Egghe's Derivation of the Impact Factor Distribution

Ludo Waltman and Nees Jan van Eck

ERS-2009-016-LIS

http://hdl.handle.net/1765/15184

The Value of RFID Technology Enabled Information to Manage Perishables

Michael Ketzenberg, and Jacqueline Bloemhof

ERS-2009-020-LIS

http://hdl.handle.net/1765/15412 
The Environmental Gains of Remanufacturing: Evidence from the Computer and Mobile Industry J. Quariguasi Frota Neto, and J.M. Bloemhof

ERS-2009-024-LIS

http://hdl.handle.net/1765/15912

Economic Modeling Using Evolutionary Algorithms: The Effect of a Binary Encoding of Strategies Ludo Waltman, Nees Jan van Eck, Rommert Dekker, and Uzay Kaymak ERS-2009-028-LIS http://hdl.handle.net/1765/16014

Language Selection Policies in International Standardization - Perception of the IEC Member Countries Hans Teichmann and Henk J. de Vries ERS-2009-031-LIS

http://hdl.handle.net/1765/16038

Dominant Design or Multiple Designs: The Flash Memory Card Case

Henk J. de Vries, Joost P.M. de Ruijter and Najim Argam

ERS-2009-032-LIS

http://hdl.handle.net/1765/16039

Standards Education Policy Development: Observations based on APEC Research

Donggeun Choi, Henk J. de Vries and Danbee Kim

ERS-2009-033-LIS

http://hdl.handle.net/1765/16040

* A complete overview of the ERIM Report Series Research in Management: https://ep.eur.nl/handle/1765/1

ERIM Research Programs:

LIS Business Processes, Logistics and Information Systems

ORG Organizing for Performance

MKT Marketing

F\&A Finance and Accounting

STR Strategy and Entrepreneurship 